\title{
A multi-platform investigation of midlatitude sporadic $E$ and its ties to $E-F$ coupling and meteor activity
}

\author{
Joseph Helmboldt \\ US Naval Research Laboratory, Code 7213, 4555 Overlook Ave. SW, Washington, DC 20375, USA \\ Correspondence to: Joseph Helmboldt (joe.helmboldt@ nrl.navy.mil)
}

Received: 4 February 2016 - Revised: 20 April 2016 - Accepted: 24 April 2016 - Published: 10 May 2016

\begin{abstract}
This paper describes the results of a multiplatform observing campaign aimed at studying midlatitude sporadic $E\left(E_{\mathrm{S}}\right)$ and associated ionospheric phenomena. The assets used were the digisonde in Boulder, Colorado; the first station of the Long Wavelength Array, LWA1, in New Mexico; the transmitters of the radio station WWV in Colorado; and 61 continuously operating GPS receivers between LWA1 and WWV. The results show that southwestward-directed medium-scale traveling ionospheric disturbances (MSTIDs) were substantially more prevalent when $E_{\mathrm{s}}$ was detected. The amplitudes of these correlate with a plasma frequency up to about $4.5 \mathrm{MHz}$. For $f_{\mathrm{p}} \gtrsim 5 \mathrm{MHz}$, the MSTIDs become significantly weaker and basically vanish above $\sim 6.5 \mathrm{MHz}$. The prevalence of meteor trail reflections observed with LWA1 also correlates with $f_{\mathrm{p}}$ up to about $4.5 \mathrm{MHz}$; above this limit, the relationship exhibits a significant turnover. The observed intensity of coherent backscatter from $E_{\mathrm{S}}$ field-aligned irregularities (FAIs) also correlates with inferred plasma frequency. However, this trend continues to higher frequencies with a peak near $6 \mathrm{MHz}$, followed by a much more subtle turnover. The reflected power from $E_{\mathrm{s}}$ structures observed with LWA1 is significantly more correlated on spatial scales between 10 and $40 \mathrm{~km}$. The magnitude of this correlation increases with $f_{\mathrm{p}}$ up to $\sim 6 \mathrm{MHz}$, above which it drops. These results are consistent with the following: (1) southwestwarddirected MSTIDs are produced via $E-F$ coupling; (2) this coupling is stronger when the $E_{\mathrm{S}}$ layer, seeded by meteor ablation, is more dense; (3) the coupling is substantially diminished for $E_{\mathrm{S}}$ layers harboring extremely dense structures $\left(f_{\mathrm{p}} \gtrsim 5 \mathrm{MHz}\right)$.
\end{abstract}

Keywords. Ionosphere (ionospheric irregularities; midlatitude ionosphere; plasma waves and instabilities)

\section{Introduction}

Midlatitude sporadic $E\left(E_{\mathrm{S}}\right)$ is a well-known ionospheric phenomenon. As the name suggests, $E_{\mathrm{S}}$ appears at $E$-region heights $(\sim 100-120 \mathrm{~km})$ intermittently throughout the year, most prominently during summer nighttime, especially in the Northern Hemisphere (e.g., Arras et al., 2010). Fundamental to its existence are tidally induced, zonal wind shears that compress metallic ions into a relatively thin region via a combination of ion-neutral collision-generated currents and $E \times B$ force. (For a much more thorough review of the processes involved, see Haldoupis, 2012). Consequently, the deposition of heavy ions within the $E$ region by ablating meteors may play a key role in $E_{\mathrm{S}}$ formation. Interestingly, some investigations found no observational evidence of a correlation between meteor activity and $E_{\mathrm{s}}$ (e.g., Baggaley and Steel, 1984; Whitehead, 1989). However, some instances of positive correlation between $E_{\mathrm{s}}$ and meteor activity have been observed (e.g., Haldoupis et al., 2007), and there is some indication that the occurrence of $E_{\mathrm{S}}$ is enhanced during meteor showers (Chandra et al., 2001; Yellaiah et al., 2001).

While these thin $E_{\mathrm{S}}$ structures are oftentimes spoken of in terms of "layers", it has been known for decades that $E_{\mathrm{S}}$ is, in fact, quite patchy (e.g., Miller and Smith, 1978). In particular, ionograms demonstrate that the maximum frequency reflected by $E_{\mathrm{S}}$ (foEs) is nearly always larger than the so-called blanketing frequency (fbEs), the frequency below which reflections from higher altitudes are not detected.

The spotty nature of $E_{\mathrm{s}}$ is also related to a phenomenon seen within radar observations, referred to as quasi-periodic (QP) echoes. QP echoes typically appear at intervals of roughly $10-15 \mathrm{~min}$, spaced by $\sim 10 \mathrm{~km}$ from one another (e.g., Bowman, 1989; Pan and Tsunoda, 1998; Hysell and Burcham, 1999). These structures are thought to arise through ion-neutral coupling within the lower ionosphere 
when turbulent, billowy structures form within the neutral gas due to Kelvin-Helmholtz (K-H) instabilities associated with the same zonal wind shears that form the $E_{\mathrm{S}}$ layers (e.g., Larsen, 2000; Bernhardt, 2002; Hysell et al., 2012). Alternatively, it has been demonstrated that structures on similar scales can be produced by an instability resulting from the wind shears that form $E_{\mathrm{s}}$ layers that favors the growth of perturbations that are aligned northwest to southeast in the Northern Hemisphere (Cosgrove and Tsunoda, 2002). There is some observational evidence from radar imaging for southwestward-propagating wavelike structures traced by $E_{\mathrm{s}}$ irregularities (e.g., Hysell et al., 2004; Larsen et al., 2007). However, other propagation directions or orientations were also observed, indicating that other structure-forming mechanisms must also be at play. It has been shown that the polarized electric fields that fuel the Cosgrove and Tsunoda (2002) instability can remotely interact with similar fields formed by the Perkins instability (Perkins, 1973) in the $F$ region, using both physical arguments (Cosgrove et al., 2004) and simulations (Cosgrove, 2007; Yokoyama et al., 2009). This $E-F$ coupling instability has been posited to be the origin of southwestwardpropagating traveling ionospheric disturbances (TIDs) seen prominently during summer nighttime in the Northern Hemisphere (e.g., Hernández-Pajares et al., 2006; Tsugawa et al., 2007). The growth rate of the Perkins instability alone has been noted to be too low to generate these $F$-region wavefronts, making the coupled $E-F$ instability, which has a larger growth rate by a factor of a few (Cosgrove et al., 2004), a more likely candidate. The fact that these TIDs are often coincident in time with $E_{\mathrm{S}}$ (e.g., Helmboldt, 2012) is consistent with this hypothesis.

The details of $E-F$ coupling are unclear as elucidative observations remain scant (for a review, see Cosgrove, 2013). In particular, the complicated state of $E_{\mathrm{S}}$ is far from the idealized initial layer used in calculations (e.g., Cosgrove et al., 2004; Yokoyama et al., 2009). There is some observational evidence that suggests that $E-F$ coupling is disrupted when higher densities are present within the $E_{\mathrm{S}}$ layer (Helmboldt, 2012), consistent with some simulated results (Cosgrove, 2007). However, it is not clear if these higher densities are caused by clumpy structures associated with, for example, $\mathrm{K}-\mathrm{H}$ instabilities or with $E_{\mathrm{S}}$ layers that are simply nonuniform in nature.

This paper presents the results of an observing campaign conducted in the summer of 2013, intended to shed light on these open questions. The analysis presented here is a combination of data from different remote sensing platforms used to simultaneously monitor for and measure the properties of $E_{\mathrm{s}}$ as well as meteor trail activity and TIDs in the form of wavelike fluctuations in total electron content (TEC). The sensors (and transmitters) involved and the observations made are described in Sect. 2. The results are presented in Sect. 3, and their implications are discussed in more detail in Sect. 4.

\section{Instruments, observations, and processing}

The $E_{\mathrm{S}}$ investigation presented here relies on what are essentially three independent remote sensing platforms. They are used together to monitor the same region (Colorado and northern New Mexico) for $E_{\mathrm{s}}$, meteor trails, and mediumscale TIDs (MSTIDs; wavelengths $\sim 100-500 \mathrm{~km}$ ). The details of the instruments involved and the observations conducted are given below.

\subsection{LWA1, WWV, FAIs, and meteor trails}

At the heart of this program are six observing runs conducted in summer 2013 with the first station of the Long Wavelength Array, LWA1. A $100 \mathrm{~m}$ diameter array of 256 bent-dipole antennas, LWA1 is the first station within what is intended to be a larger array of more than 50 similar stations spread throughout New Mexico for high-angularresolution imaging of cosmic sources in the HF/VHF (highfrequency-very high-frequency) regime. While the future of the full LWA is uncertain, LWA1 is currently run as a standalone observatory (at $\phi=34.070^{\circ} \mathrm{N}, \lambda=107.628^{\circ} \mathrm{W}$ ), capable of operating within the $10-88 \mathrm{MHz}$ range in one of three modes. These include a relatively wide-band $(16 \mathrm{MHz})$ beam-forming mode and two transient buffer (TB) modes that each capture the signals from individual antennas, allowing for all-sky imaging after the fact. For more details of the LWA1 radio telescope, see Hicks et al. (2012), Taylor et al. (2012), and Ellingson et al. (2013).

It is the all-sky TB modes that have the greatest potential for passive radar, the exploitation of transmitters of opportunity to illuminate a given target. In this case, the "targets" are $E_{\mathrm{s}}$ layers and meteor trails. Specifically, Helmboldt et al. (2013) showed that the HF transmitters of the NIST radio station WWV near Ft. Collins, Colorado (see Fig. 1), could be used with LWA1's TB modes to probe the ionosphere. WWV broadcasts the time at 2.5, 5, 10,15, and $20 \mathrm{MHz}$, including a $5 \mathrm{~ms}$ pulse at the beginning of each UT second (Nelson et al., 2005) that can be used for ranging. The frequency overlap between LWA1 and WWV is thus at 10,15 , and $20 \mathrm{MHz}$. Sky waves from WWV are often observed at $10 \mathrm{MHz}$, either from the lower $F$ region or from $E_{\mathrm{s}}$. The geometry is such that 15 and $20 \mathrm{MHz}$ sky waves can only originate from dense, low-altitude $(\sim 100 \mathrm{~km})$ plasma, i.e., $E_{\mathrm{s}}$.

The LWA1+WWV passive radar works with both the wide-band and narrow-band TB modes (TBW and TBN, respectively). The TBW mode produces a $61 \mathrm{~ms}$ capture of the raw signal from each antenna, allowing access to the full band $(10-88 \mathrm{MHz})$ for all-sky imaging. Unfortunately, the time it takes to write this data to disk (nearly $10 \mathrm{~GB}$ for one capture) is so long ( $\sim 5 \mathrm{~min})$ that the duty cycle is rather low. With the TBN mode, each antenna's signal is tuned to a selected frequency with $100 \mathrm{kHz}$ of bandwidth $(\sim 70 \mathrm{kHz}$ is actually usable) that can be run continuously for up to $20 \mathrm{~h}$ (when the available disks fill up). 


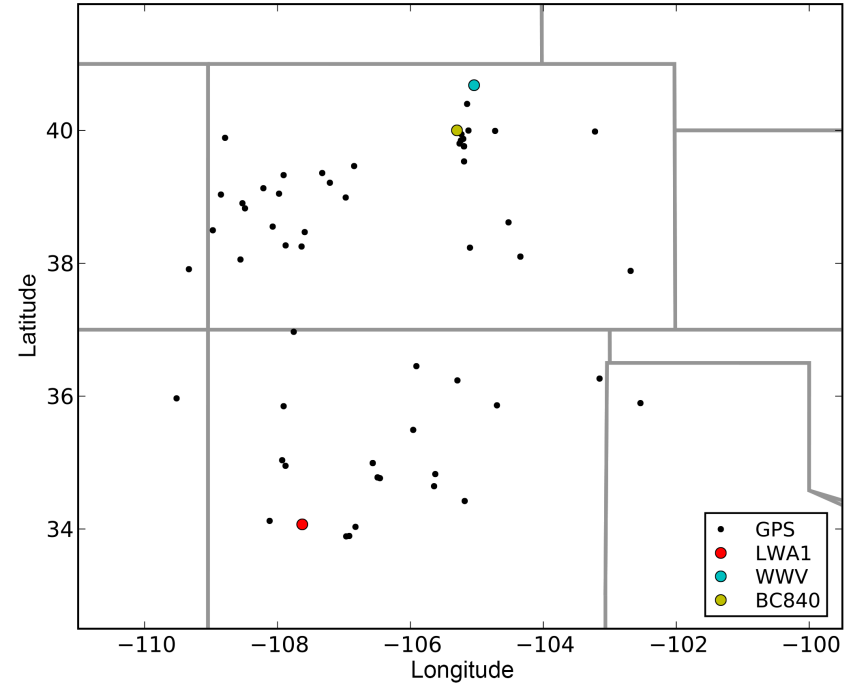

Figure 1. Locations of the remote sensing platforms used in this study including 61 continuously operating GPS receivers (black points), the Boulder digisonde (BC840; yellow), LWA1 (red), and the WWV transmitters (cyan).

Using either mode, the antenna outputs are processed to isolate the WWV pulse at different group paths and are then used to generate image cubes that show the received pulse power over the entire visible sky at each group path. From these, one can measure the altitude, azimuth, and group path of any detected sky wave. Consequently, with TBW captures, one can simultaneously measure sky wave properties at 10 , 15 , and $20 \mathrm{MHz}$, but only every 5-6 min. Conversely, TBN data allows one to do the same with $1 \mathrm{~s}$ sampling, but only at a single frequency. In either case, the combined radar is quite useful for observing $E_{\mathrm{s}}$, especially at 15 and $20 \mathrm{MHz}$. In particular, the all-sky imaging capability and bistatic nature of the LWA1+WWV system manifest a probe of $E_{\mathrm{s}}$ structures that can pinpoint their horizontal positions to a precision as good as $1 \mathrm{~km}$ over a relatively large area $(\sim 100 \mathrm{~km}$ wide and several hundred kilometers long). This is discussed at greater length by Helmboldt et al. (2013).

All-sky imaging with LWA1 can similarly be used to detect, locate, and characterize VHF transmissions backscattered by field-aligned irregularities (FAIs) and/or meteor trails. For the right bistatic configuration, ionospheric structures with small-scale irregularities (half the observing wavelength) aligned along magnetic field lines will Bragg scatter signals to the receiver array. In addition to FAIs, meteor trails collectively act as a persistent source of VHF backscatter. As meteors ablate in the lower ionosphere $(\sim 80-100 \mathrm{~km})$, they produce dense, transient structures that are nearly linear and can produce specular reflections of VHF radiation.

For LWA1, there is a relatively nearby and powerful analog TV transmitter located in Ciudad Juárez, Mexico, roughly $280 \mathrm{~km}$ south-southeast of LWA1. According to the Federal
Communications Commission (FCC), the effective radiative power (ERP) of this nondirectional, horizontally polarized transmitter (call sign XEPM) is $9.5 \mathrm{~kW}$. It broadcasts on "Channel 2" with a very narrow-band, amplitude-modulated video carrier at 55.25 MHz. Helmboldt et al. (2014) demonstrated that using this video carrier, $\gtrsim 9000$ meteor trails can be detected and located on the sky per hour using LWA1 TBN data. This is well over an order of magnitude larger that the count rates achieved with more commonly utilized dipolebased, all-sky meteor radars such as the Canadian Meteor Orbit Radar (CMOR) arrays and All-Sky Interferometric Meteor Radar (SKiYMET) systems $\left(\sim 100-300 \mathrm{~h}^{-1}\right.$ near local midnight; Hocking et al., 2001; Webster et al., 2004). The data processing and imaging pipeline developed by Helmboldt et al. (2014) can also be used to identify and track FAIs along arcs in the sky north of the array where backscattering is possible. At $55.25 \mathrm{MHz}$, LWA1 has an angular resolution on the sky of about $3.1^{\circ}$. This is comparable to the azimuthal resolution $\left(\sim 4^{\circ}\right)$ of the $30 \mathrm{MHz}$ imaging radar deployed in St Croix (US Virgin Islands) in 2002 and used to study backscatter from $E_{\mathrm{s}}$ irregularities over Puerto Rico, i.e., at a latitude not dissimilar to LWA1 (see, e.g., Hysell et al., 2004; Larsen et al., 2007).

For FAI and meteor trail observing alone, the complementary TBW mode offers no apparent advantages over the TBN mode. However, for the purpose of examining how meteor activity impacts $E_{\mathrm{s}}$ while also detecting and characterizing FAIs associated with $E_{\mathrm{S}}$, the extremely wide bandwidth of the TBW mode offers a singularly useful kind of data set. With a series of TBW captures, one can simultaneously observe specular meteor trail reflections, $E_{\mathrm{s}}$ reflections of WWV pulses at 10,15 , and $20 \mathrm{MHz}$, and VHF backscatter from $E_{\mathrm{S}}$ FAIs. With this motivation, time was obtained with LWA1 for six observing runs in 2013 during summer nighttime when $E_{\mathrm{S}}$ is most prevalent. Specifically, each run consisted of a series of $80 \mathrm{TBW}$ captures spaced by $6 \mathrm{~min}$ from 03:00 to 11:00 UT (roughly 19:50 to 03:50 local time). The observations were conducted on 23 June; 21 July; 4, 13, and 21 August; and 1 September (or, as days of the year, on DOY 174, 202, 216, 225, 233, and 244).

The data were processed with python-based software, including the LWA Software Library (LSL; Dowell et al., 2012), to produce all-sky or group path image cubes using WWV pulses at 10,15, and $20 \mathrm{MHz}$. These cubes were analyzed according to Helmboldt et al. (2013) to measure the sky location and group path of each WWV reflection. To monitor for FAIs and meteor trails, all-sky images were also produced within 45 frequency channels, centered at $55.25 \mathrm{MHz}$ and spaced by $16.33 \mathrm{~Hz}$, covering a range in Doppler speed of about $\pm 1000 \mathrm{~m} \mathrm{~s}^{-1}$ with a resolution of roughly $90 \mathrm{~m} \mathrm{~s}^{-1}$. To convert these spectral images into all-sky maps of backscattered signals, the image for each channel was normalized by its noise level, estimated with the median absolute deviation (MAD). These signal-to-noise $(S / N)$ all-sky maps were then 
converted to a single peak $S / N$ map for each TBW capture by simply computing the maximum $S / N$ over all channels at each all-sky pixel. This was done to mitigate the effect of very bright meteor trails which artificially increase the noise within an image because of the sidelobes associated with the LWA1 beam. Because the video carrier signal is inherently quite narrow $(\sim 20-30 \mathrm{~Hz})$, this typically only affects 1-3 channels near the Doppler frequency of a bright trail. Thus, this $S / N$-based approach allows fainter sources at significantly different Doppler frequencies to still be detected. A similar technique used to maximize meteor trail detections with TBN data is detailed in the Appendix of Helmboldt et al. (2013).

\subsection{Boulder digisonde and GPS}

Supplementing the LWA1 observations and data products are two additional remote sensing assets. The first is the digital ionosonde, or "digisonde", near Boulder, Colorado (station ID BC840). The location of BC840 relative to LWA1 and WWV is shown in Fig. 1. Ionogram data (frequencies, ranges, and amplitudes) were obtained for BC840 for the times during the LWA1 observations from the Digital Ionogram Database (DIDBase; Reinisch et al., 2004), except for 23 June (DOY: 174) when no BC840 data were available. From these, mean ionograms were produced within half-hour intervals during all but the first observing run. Visual inspection of these revealed the signature of $E_{\mathrm{S}}$ during many of the observations below virtual heights of $122 \mathrm{~km}$.

The second asset is an array of continuously operating GPS receivers. These were chosen from the publicly accessible Continuously Operating Reference Station (CORS) (ftp://www.ngs.noaa.gov/cors/rinex/) and UNAVCO (ftp:// data-out.unavco.org/pub/rinex/) databases. All stations from these repositories that were within $400 \mathrm{~km}$ of the midpoint between LWA1 and WWV were chosen so that they would cover roughly the same area as the LWA $1+\mathrm{WWV}$ radar (the separation between LWA1 and WWV is $770 \mathrm{~km}$ ) and BC840. The 61 stations that meet this criterion are almost exclusively in Colorado and northern New Mexico; their exact locations are shown in Fig. 1.

Data for the GPS array were obtained in Receiver Independent Exchange (RINEX) format for the dates of the LWA1 observing run. These were processed with software available within the GPS Toolkit (GPSTk; Tolman et al., 2004) to generate relative slant TEC (STEC) time series for each receiver-satellite pair. To remove instrumental biasses and to focus on TEC fluctuations, these STEC time series were detrended according to Hernández-Pajares et al. (2006). Within this de-trending scheme, at each time step, the average between the time steps that are $\tau$ seconds before and after the time step is subtracted, where $\tau$ is a flexible timescale. This finite differencing method has the drawbacks of increasing the noise somewhat (by a factor of about $\sqrt{1.5}=1.22$ ) and rendering the first and last $\tau$ seconds of each time series use- less. However, the chief advantage is that it produces a predictable temporal frequency response: $2 \sin ^{2}(\pi \tau \nu)$, where $v$ is the temporal frequency. In other words, a TEC fluctuation with a period of $v^{-1}$ and amplitude $A$ will have a modified amplitude $A^{\prime}=2 A \sin ^{2}(\pi \tau \nu)$ after de-trending is applied. Thus, the choice of $\tau$ allows one to tune the GPS data to a particular range of fluctuation periods or frequencies. This is especially important for the spectral analysis that will be used to characterize TIDs.

For each satellite, a three-dimensional Fourier analysis was performed over the array, with one temporal dimension and two spatial ones. For this, each de-trended STEC time series was broken into 30 min segments, overlapping with the mean ionograms produced with the $\mathrm{BC} 840$ data. Each segment was then analyzed according to Helmboldt and Intema (2014). This starts with a straightforward temporal discrete Fourier transform, followed by a specialized spatial Fourier analysis meant to deal with the consequences of the sparse and irregular nature of the GPS array that was used. This includes the incorporation of deconvolution techniques developed and thoroughly tested within the field of radio astronomy for the similar problem of generating synthesis images of cosmic sources with radio-frequency interferometers. These techniques mitigate the impact of high-frequency structures caused by the array geometry (i.e., sidelobes) as well as phase errors caused mainly by wavefront distortions and/or point-of-view effects that vary in magnitude over the array. See Helmboldt and Intema (2014) for a much more detailed description. The end product of this analysis is a power spectrum cube (again, one temporal frequency axis and two spatial frequency axes) of TEC fluctuations within each 30 min segment.

During the application of this process, different values for the de-trending timescale, $\tau$, were tried. In the end, $\tau=600 \mathrm{~s}$ was adopted as it appeared to provide the optimum temporal frequency response for MSTIDs during the LWA1 observations, similar to what was found by Helmboldt et al. (2012) in the same geographic region. The analysis was also limited to times when the observed satellites were above $30^{\circ}$ elevation to avoid biases resulting from extreme line-of-sight effects and to ensure that the area of the ionosphere being probed was reasonably similar to that observed with LWA1+WWV and BC840.

\section{TIDs, meteors, and sporadic- $E$ properties}

To examine how southwestward-directed MSTIDs and levels of meteor activity relate to $E_{\mathrm{s}}$, the data products described in Sect. 2 were combined to yield average representations according to $E_{\mathrm{s}}$ properties as measured with LWA1+WWV and BC840. As an initial trial, the GPS-based TEC fluctuation spectrum cubes were divided into four groups: two groups with concurrent $E_{\mathrm{s}}$ detections from either LWA1 or 


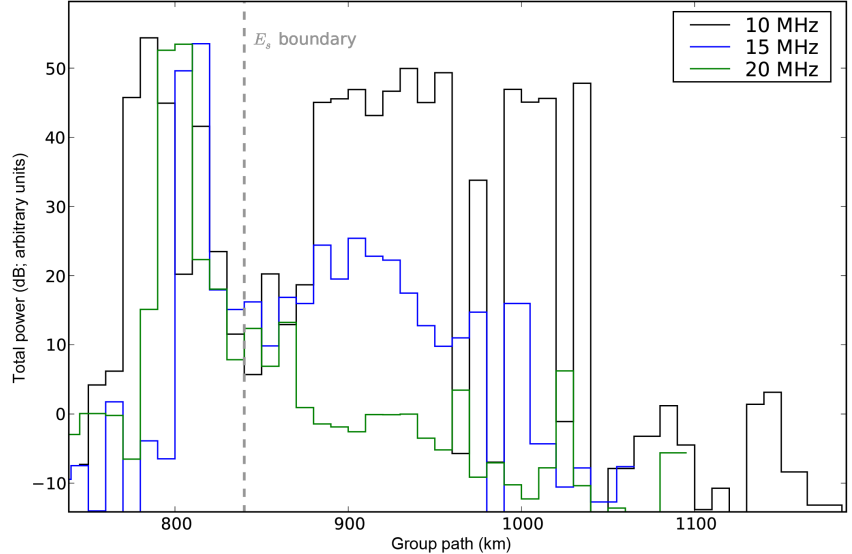

Figure 2. The total received power from WWV at LWA1 at 10, 15 , and $20 \mathrm{MHz}$ (black, blue, and green lines, respectively) within bins of group path over all six observing runs (see Sect. 2). The adopted group path upper boundary for $E_{\mathrm{S}}, 840 \mathrm{~km}$ (virtual height $\sim 170 \mathrm{~km}$ ), is shown as a grey dashed line.

BC840 and two complementary groups without $E_{\mathrm{S}}$ detections.

\section{1 $E-F$ coupling}

For the LWA1+WWV observations, $E_{\mathrm{s}}$ detections and nondetections were assessed based on the group path measured for the $10 \mathrm{MHz}$ sky waves. The distributions of returned power within bins of group path for 10,15 , and $20 \mathrm{MHz}$ are shown in Fig. 2. The $20 \mathrm{MHz}$ distribution was scaled by a factor of 4 because the $20 \mathrm{MHz}$ transmitter has an ERP 4 times lower than the other two $(2.5$ vs. $10 \mathrm{~kW})$. One can see that virtually all the returned power at 15 and $20 \mathrm{MHz}$, reflections of which are (nearly) always from $E_{\mathrm{s}}$, is at group paths below $840 \mathrm{~km}$. There is a small amount of power from "two-hop" signals - those that reflect off the ionosphere, then off the ground, then off the ionosphere again - but generally, the $840 \mathrm{~km}$ group path provides a good cutoff to distinguish between $E_{\mathrm{s}}$ and $F$-region reflections at $10 \mathrm{MHz}$. Note that the linear distance between LWA 1 and WWV is $770 \mathrm{~km}$, implying that a group path of $840 \mathrm{~km}$ corresponds to a virtual height of about $170 \mathrm{~km}$. This is a bit high for $E_{\mathrm{s}}$, but one should note that this empirical limit essentially takes into account uncertainties within the group path measurements and the fact that a virtual mirror approximation is a poor representation of the often complex signal path associated with propagation through intricate $E_{\mathrm{s}}$ structures.

For the BC840 data, the $30 \mathrm{~min}$ average ionograms were used to determine during which time periods $E_{\mathrm{S}}$ was and was not present. Average TEC fluctuation spectral cubes were made for the four groups (two with $E_{\mathrm{s}}$ and two without), and a map of the peak spectral power over all temporal frequencies is shown for each in Fig. 3. These maps show the maximum spectral power as functions of east-west
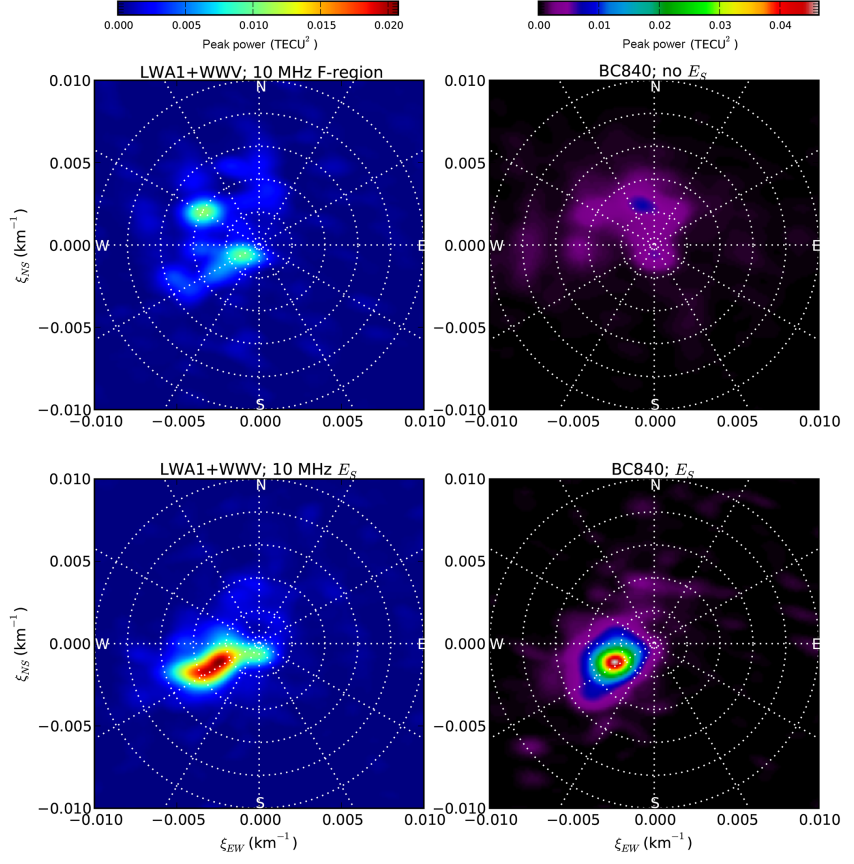

Figure 3. The peak TEC fluctuation power over all temporal frequencies from averaged power spectrum cubes generated using data from the array of the 61 GPS receivers shown in Fig. 1. The results from four different mean spectral cubes are shown: (upper left) using only GPS data from times when likely $F$-region reflections were detected at $10 \mathrm{MHz}$ with the LWA1+WWV radar; (lower left) times when $E_{\mathrm{S}}$ reflections were detected at $10 \mathrm{MHz}$ with LWA1+WWV; (upper right) times when no $E_{\mathrm{S}}$ was visible within the BC840 ionograms; and (lower right) times when $E_{\mathrm{S}}$ was apparent in the BC840 ionograms.

and north-south spatial frequencies $\left(\xi_{\mathrm{EW}}\right.$ and $\left.\xi_{\mathrm{NS}}\right)$. Polar grids are shown for reference at radial steps of $0.002 \mathrm{~km}^{-1}$. For reference, the spectral resolution within these maps is roughly $0.0015 \mathrm{~km}^{-1}$ (full width at half maximum).

The two non- $E_{\mathrm{s}}$ spectra show relatively weak signatures (amplitudes $\lesssim 0.08$ TECU) of waves moving in several directions. These include MSTIDs (wavelengths $\sim 250-350 \mathrm{~km}$ ) moving westward, northwestward, northward, and northeastward and larger TIDs $(\sim 1000 \mathrm{~km}$ wavelength) moving due south. There is also a relatively weak signature of $\sim 1000 \mathrm{~km}$ wavelength TIDs moving toward the southwest seen only within the LWA1+WWV non- $E_{\mathrm{S}}$ spectral map. The fact that it is only seen within this map may be related to contamination from two-hop $E_{\mathrm{s}}$ reflections that were incorrectly flagged as $F$-region sky waves due to their larger group paths (see above and Fig. 2).

The two $E_{\mathrm{s}}$ maps are markedly different from their non- $E_{\mathrm{s}}$ counterparts. They both exhibit quite prominent features associated with southwestward-directed MSTIDs. Save a single, relatively weak, southward-directed, large TID feature seen in the LWA1+WWV map, these are essentially the only significant features apparent within the two maps. The 
main differences in these features between the two maps is that the TID feature is stronger within the BC840 map (amplitude $\sim 0.22 \mathrm{TECU}$; note, the figures display fluctuation power as amplitude ${ }^{2}$ ) and peaked near a single wavelength $(\sim 350 \mathrm{~km})$. In contrast, the southwest feature in the LWA1+WWV map is distributed among a somewhat larger range of wavelengths $(\sim 250-500 \mathrm{~km})$, with peak power corresponding to amplitudes of about 0.15 TECU. Despite these differences, the occurrences of dominant southwest-directed features within spectra corresponding to $E_{\mathrm{s}}$ detections and the virtual absence of such features within the non- $E_{\mathrm{S}}$ spectra together confirm earlier, similar results (Helmboldt, 2012; Cosgrove, 2013) that are consistent with the existence of some form of $E-F$ coupling.

To further explore how this correlation between the appearance of $E_{\mathrm{S}}$ and $F$-region MSTIDs relates to the properties of the $E_{\mathrm{S}}$ layers, weighted mean spectra, similar to those shown in Fig. 3, were made using the signal amplitude at different frequencies. For the LWA1+WWV data, different mean spectra were made using the 10, 15, and $20 \mathrm{MHz}$ sky wave amplitudes as weights. For the $10 \mathrm{MHz}$ sky waves, only those with group paths $<840 \mathrm{~km}$ were used (see above). The resulting spectra are shown in the left panels of Fig. 4. From these, one can see that the TID amplitude increases with the reflection frequency and, implicitly, with $E_{\mathrm{S}}$ density. At higher frequency or density, it also appears that the MSTIDs are skewed more toward somewhat smaller wavelengths $(\sim 250 \mathrm{~km})$. Separate mean fluctuation spectra were made using $E_{\mathrm{s}}$ signal amplitudes from the BC840 ionograms, averaged within five different frequency bins. Four evenly spaced bins were used between 1 and $6.6 \mathrm{MHz}$ with the fifth bin including all $E_{\mathrm{S}}$ signals for $f>6.6 \mathrm{MHz}$. The first three frequency bins roughly correspond to the inferred plasma frequencies for the LWA1+WWV system at 10,15 , and $20 \mathrm{MHz}$ assuming an $E_{\mathrm{s}}$ height of $110 \mathrm{~km}$ and a simple virtual mirror approximation. These first three bins show a similar, but more pronounced trend of increasing fluctuation power with increasing $E_{\mathrm{s}}$ frequency as is apparent from the LWA1+WWV weighted spectra. However, no comparable change in dominant wavelength is evident. Within the mean spectrum for the next highest frequency bin, $5.2-6.6 \mathrm{MHz}$, the wave amplitudes are significantly weaker, and for the largest frequency bin, the southwestward-directed MSTIDs are virtually nonexistent. This is similar to the results presented by Helmboldt (2012), which showed a decrease in MSTID activity for foEs $>3 \mathrm{MHz}$.

\subsection{Meteor trails and FAIs}

An analysis similar to that presented in Sect. 3.1 for the GPS-based TEC fluctuation spectra was performed on the all-sky $55.25 \mathrm{MHz} S / N$ maps described in Sect. 2.1. Figure 5 shows mean $S / N$ maps for the same $E_{\mathrm{s}}$ and non- $E_{\mathrm{s}}$ groups that are represented in Fig. 3. The region to the north
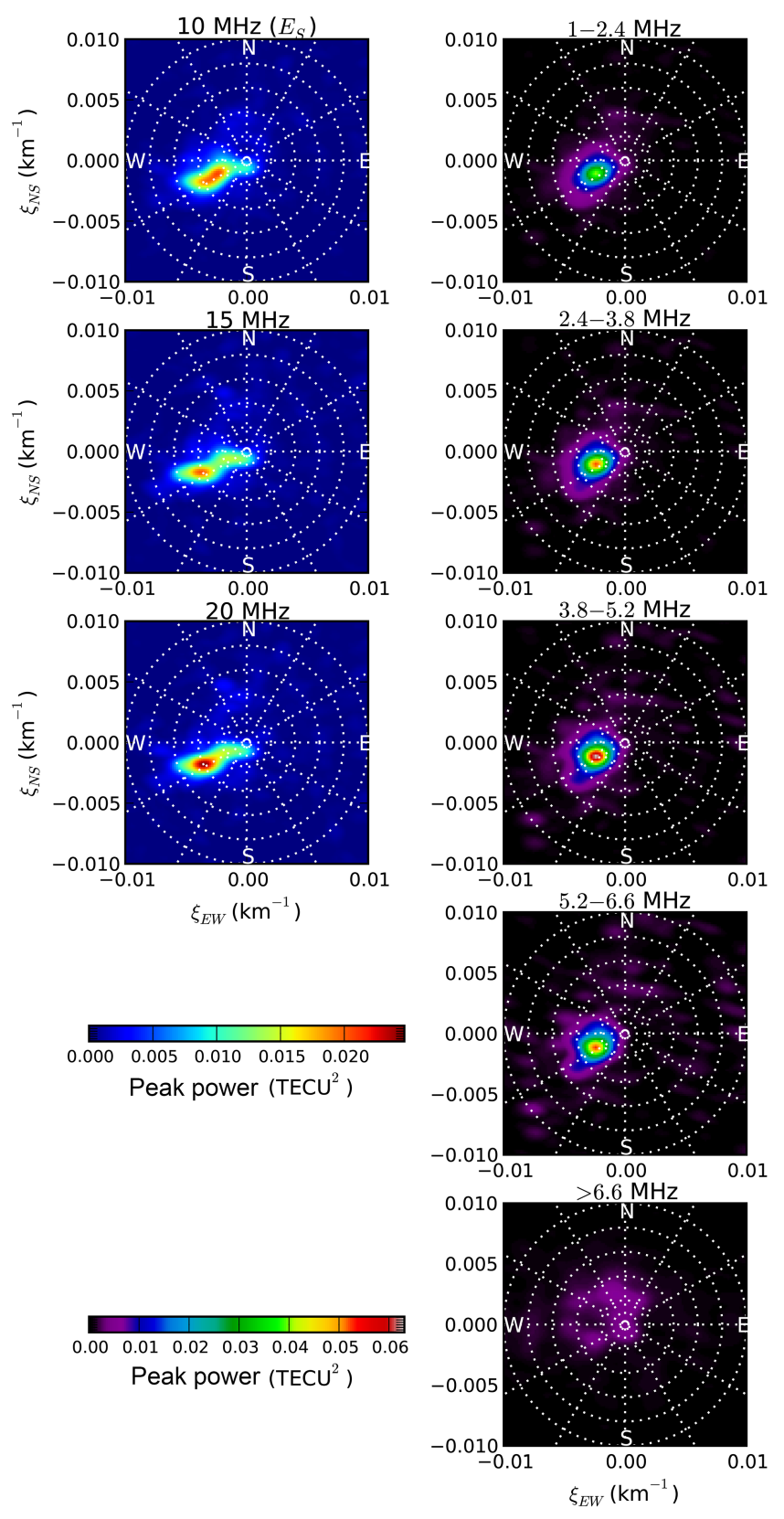

Figure 4. Similar to Fig. 3, the peak TEC fluctuation power over all temporal frequencies from averaged, GPS-based power spectrum cubes. In this case, the power spectrum cubes were generated as weighted averages where the weight was (upper left) the $10 \mathrm{MHz}$, LWA1+WWV sky wave amplitude ( $E_{\mathrm{S}}$ only), (middle left) the $15 \mathrm{MHz}$ LWA1+WWV amplitude, and (lower left) the $20 \mathrm{MHz}$ amplitude. The panels within the right column show results from weighted mean spectral cubes, weighted with the average $E_{\mathrm{S}}$ amplitude from the BC840 ionograms within frequency bins noted above each panel. 

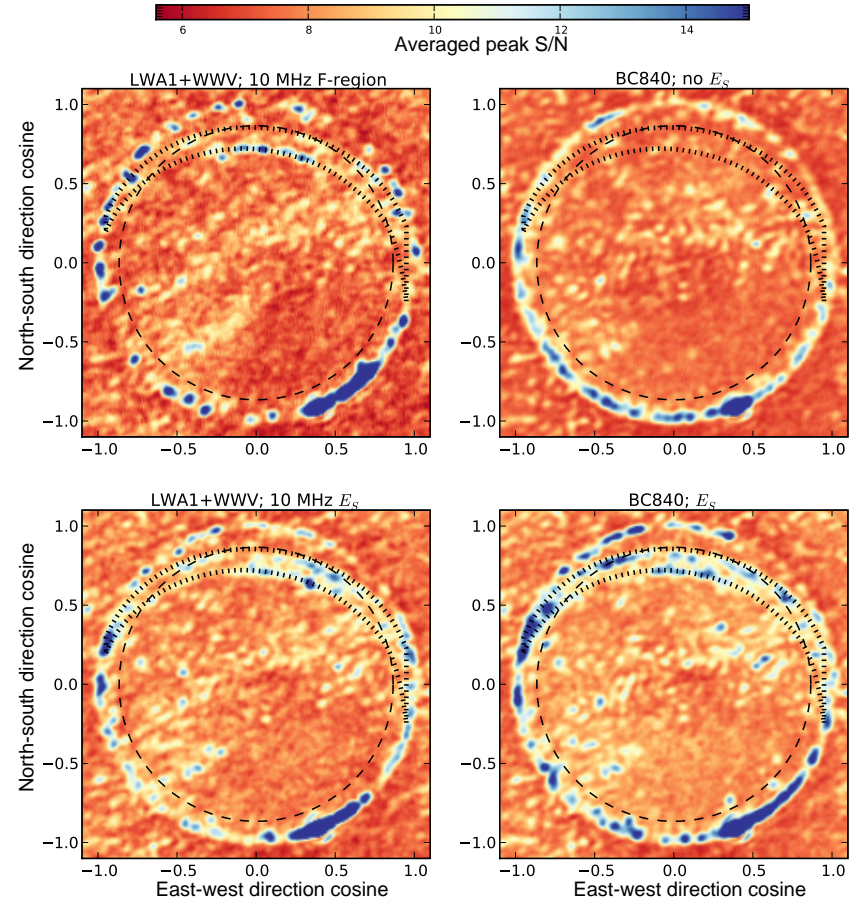

Figure 5. For the same groups of observations shown in Fig. 3, the average peak $S / N$ map for backscattered $55.25 \mathrm{MHz}$ transmissions. The region dominated by backscattering of signals from transmitters in Mexico by field-aligned irregularities (FAIs) to the north is marked by black dotted lines. This region was computed using the known transmitter location for XEPM from the FCC and heights between 90 and $130 \mathrm{~km}$. An elevation of $30^{\circ}$, above which $>80 \%$ of sources are meteor trails, is marked with a dashed black circle.

where backscattering by $E_{\mathrm{S}}$ FAIs is expected to be prevalent is marked in each panel with a black dotted line. This was computed using the location for XEPM obtained from the FCC (at $\phi=31.706^{\circ} \mathrm{N}, \lambda=106.478^{\circ} \mathrm{W}$ ), an assumed height range of $90-130 \mathrm{~km}$, and using the international geomagnetic reference field (IRGF) parameters for the 2013 epoch. While there are certainly meteor trails detected within this region on the sky, sources within this area are excluded from meteor trail analysis due to the higher likelihood that they corresponds to FAIs.

Within the panels of Fig. 5, the circle corresponding to an elevation of $30^{\circ}$ is marked with a black dashed line. Above this elevation, Helmboldt et al. (2014) found that $>85 \%$ of detected point-like sources at $55.25 \mathrm{MHz}$ are true meteor trails, based on high-resolution time series $(5.12 \mathrm{~ms}$ sampling) of signal amplitudes. Below this elevation limit, other transmitters and reflections off aircraft constitute a significant fraction of sources. An ongoing survey for meteor streams with LWA1 at $55.25 \mathrm{MHz}$ has found that more than $90 \%$ of sources above this limit have time series best explained by meteor trail reflections. Furthermore, this survey found a preponderance of sources within the likely FAI re-

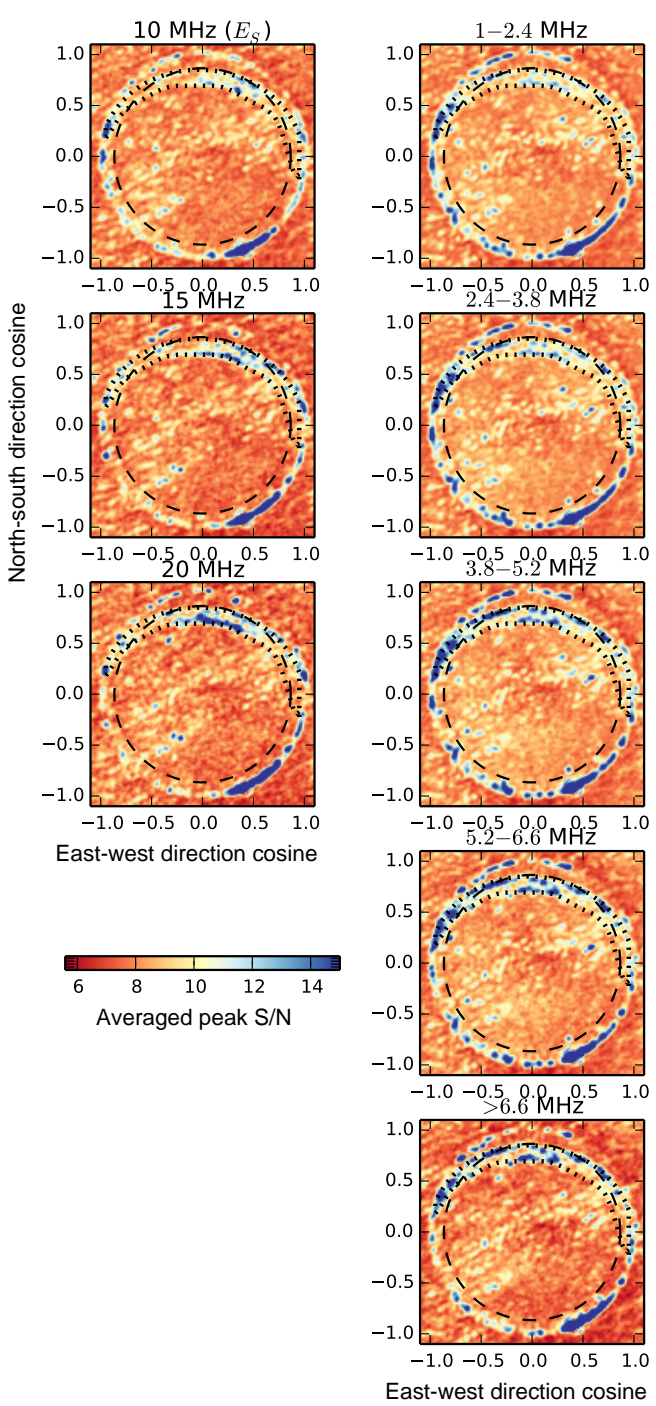

Figure 6. The weighted mean peak $S / N$ map for scattered 55.25 MHz signals using the same weighting schemes as the corresponding panels in Fig. 4.

gion in the summer of 2014 that are much longer-lived than typical meteors, consistent with $E_{\mathrm{S}}$ FAIs.

For both the LWA1- and BC840-based groups, meteor trail activity and likely FAIs were significantly more prominent when $E_{\mathrm{S}}$ was present. Like the results for MSTIDs shown in Fig. 3, this is much more pronounced within the BC840based groups. In this case, there are few if any sources above $30^{\circ}$ elevation (i.e., likely meteor trails) and the arcs likely associated with FAIs are not discernible at all in the mean $S / N$ map for the non- $E_{\mathrm{s}}$ group. Specifically, the mean $S / N$ within the FAI and meteor trail regions are 30 and $10 \%$ larger, respectively, within the $E_{\mathrm{S}}$ map versus the non- $E_{\mathrm{S}}$ map when using BC840 data, but only 10 and 5\% higher when using LWA1 data. Again, this may point to contamination within the LWA1 non- $E_{\mathrm{s}}$ group by two-hop $E_{\mathrm{s}}$ reflections. The 
FAIs that appear within these all-sky maps sometimes appear in resolved groups with elongated, wavefront-like structures. These appear to have no single dominant orientation and are generally consistent with similar observations of $E_{\mathrm{s}}$ backscatter at $30 \mathrm{MHz}$ over Puerto Rico (Hysell et al., 2004; Larsen et al., 2007; Hysell et al., 2009, 2012).

Averaged 55.25 MHz $S / N$ maps are also shown in Fig. 6, weighted by sky wave amplitudes at different frequencies. These are counterparts to the averaged TEC fluctuation spectral maps shown in Fig. 4. Here, it is evident that for both LWA1+WWV- and BC840-based averaging, both meteor trail activity and the incidence of FAIs correlate with $E_{\mathrm{S}}$ density to some degree. Specifically, the mean $S / N$ within the meteor trail region increases by a few percent from 1.5 to 4.5 MHz. The FAI region average $S / N$ increases by more than $10 \%$ from 1.5 to $6 \mathrm{MHz}$. The exact dependences on $f_{\mathrm{p}}$ will be discussed more in Sect. 4 .

\subsection{Sporadic- $E$ structure from passive radar}

The results presented within the previous two subsections imply that up to plasma frequencies of about $5 \mathrm{MHz}, E_{\mathrm{s}}$ layer density increases steadily with the level of meteor activity and that this increased density may enhance $E-F$ coupling. However, above this level, other processes must influence the structure of the $E_{\mathrm{s}}$ layers as the strength of detected MSTIDs wanes above $5 \mathrm{MHz}$ and the trend between $f_{\mathrm{p}}$ and meteor activity exhibits a similar turnover. Therefore, these relatively high $E_{\mathrm{S}}$ densities cannot be explained by increased deposition of heavy ions via meteor ablation and are likely related to some process that may also disrupt $E-F$ coupling.

To explore this further, the LWA1-WWV and BC840 data were combined to discover whether or not there is evidence for dense, isolated $E_{\mathrm{S}}$ structures that could yield highfrequency reflections but would not constitute an overall increase in the total ion content of the $E_{\mathrm{s}}$ layers. Following Helmboldt et al. (2013), we used the WWV sky waves imaged by LWA1 to localize the signals on the sky and infer the horizontal position of each $E_{\mathrm{s}}$ reflection point. This was done using the $15 \mathrm{MHz}$ data since $15 \mathrm{MHz}$ WWV reflections are all from $E_{\mathrm{S}}$, which is not the case at $10 \mathrm{MHz}$, and the $15 \mathrm{MHz}$ transmitter is 4 times more powerful than the one at $20 \mathrm{MHz}$. The positions were measured parallel and perpendicular to the great circle connecting the LWA1 and WWV positions at an altitude of $110 \mathrm{~km}$ and are plotted for each LWA1 observing run in Fig. 7, color-coded by signal amplitude. Upon visual inspection of these plots, it is clear that within a single observing run, the reflection points can be quite clustered, especially for the mid-August observing runs (DOY: 225, 233).

To quantify the level of clustering, the correlated power was computed among $15 \mathrm{MHz}$ reflections within bins of horizontal separation for each observing run, then averaged into a single correlation function. This was done by multiplying the amplitude of each $15 \mathrm{MHz}$ reflection by the amplitudes of all

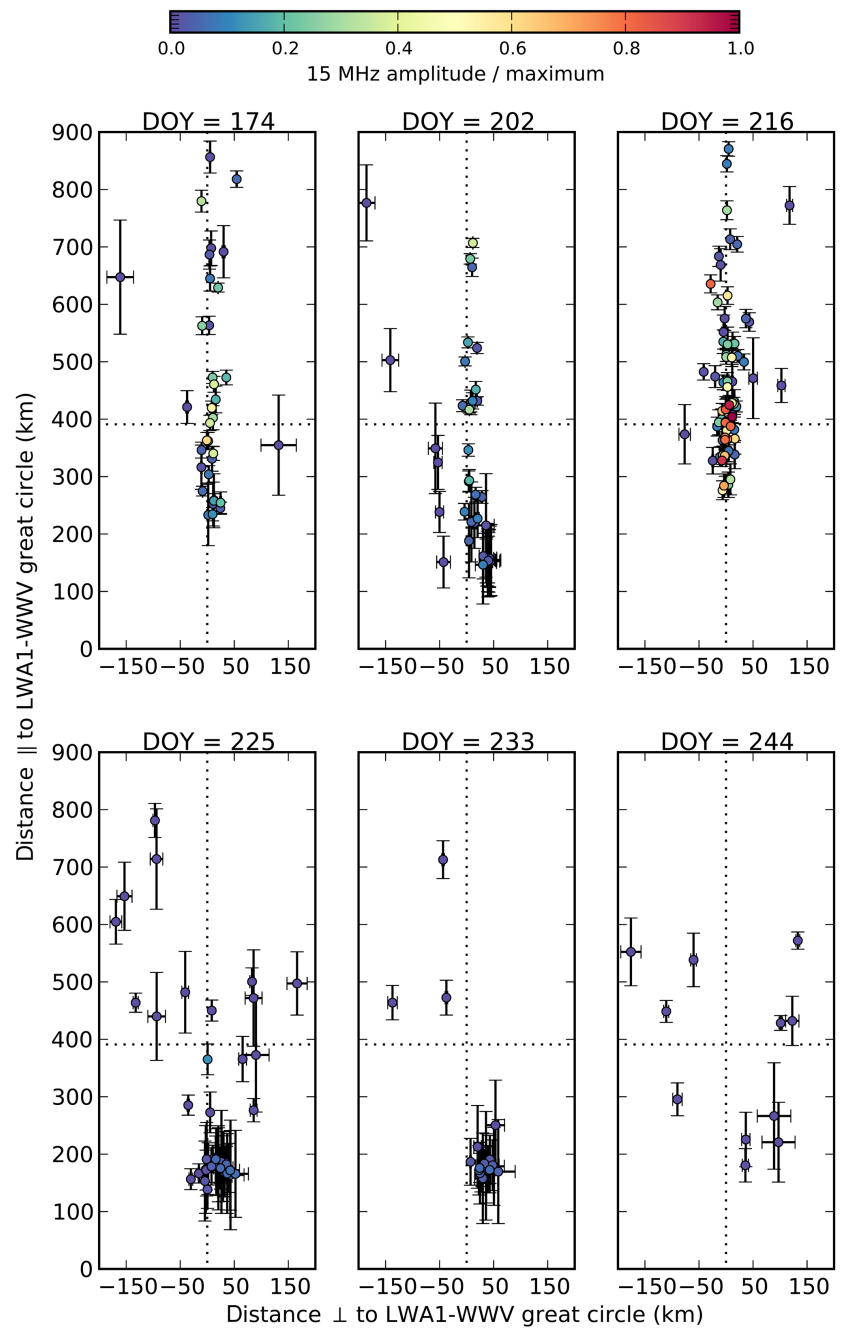

Figure 7. The horizontal locations of $E_{\mathrm{S}}$ structures reflecting $15 \mathrm{MHz}$ WWV transmissions during the six observing runs. Positions are measured as arc lengths perpendicular (abscissa) and parallel (ordinate) to the great circle connecting the latitudes and longitudes of LWA1 and WWV at a height of $110 \mathrm{~km}$ (vertical dotted line) with LWA1 at the origin. The midpoint between LWA1 and WWV is illustrated with a horizontal dotted line. The points are color-coded according to $15 \mathrm{MHz}$ sky wave amplitude; positions with $\perp$ or $\|$ uncertainties larger than 50 and $100 \mathrm{~km}$, respectively, were excluded.

others within an observing run and then summing these products with bins of horizontal separation. This was repeated for all $15 \mathrm{MHz}$ sky waves and for all observing runs and combined into a total correlation function. A normalized version of this (divided by the total over all bins) is shown in red in the panels of Fig. 8. The signals appear to be, on average, significantly correlated on horizontal scales up to about $250 \mathrm{~km}$, which is not surprising given the results shown in Fig. 7. However, the correlation is significantly stronger for separations $<150 \mathrm{~km}$, especially between 10 and $40 \mathrm{~km}$. 


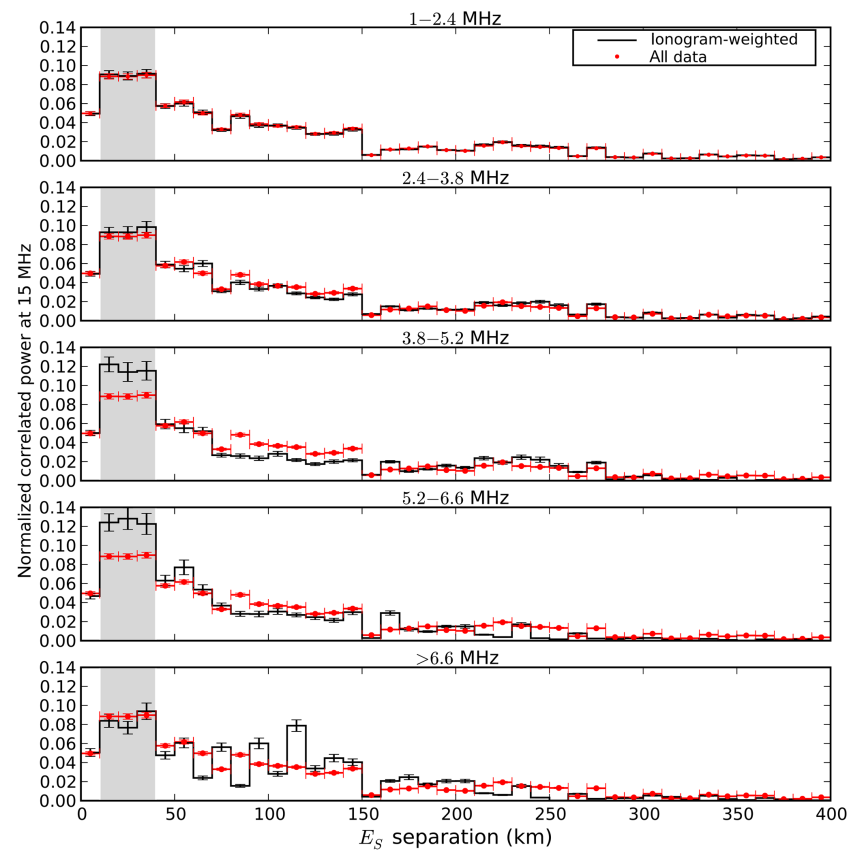

Figure 8. The mean, normalized, correlated power of $15 \mathrm{MHz}$ WWV sky waves reflected by $E_{\mathrm{S}}$ within bins of horizontal separation. The correlations were measured separately for the six observing runs and then combined. The red dots show the correlation function for all $15 \mathrm{MHz} E_{\mathrm{S}}$ reflections. Within each panel, the black histogram shows the results if the individual correlations are weighted according to the $E_{\mathrm{S}}$ amplitudes from contemporaneous BC840 ionograms within different frequency bins. The range of separations that typically shows the strongest correlation, 10 $40 \mathrm{~km}$, is highlighted in grey in all panels.

To examine how this changes with $E_{\mathrm{S}}$ layer density, the correlation function was recomputed, this time weighting the correlated power from each sky wave pair by the product of the $E_{\mathrm{s}}$ signal amplitudes from the corresponding BC840 ionograms within different frequency bins. The ionogram frequency bins used were the same as those used for Figs. 4 and 6 . The weighted and normalized correlation functions for these frequency bins are shown as black histograms in the panels of Fig. 8. One can see that correlation on $10-40 \mathrm{~km}$ scales (highlighted in grey) steadily increases with ionogram frequency up to $6.6 \mathrm{MHz}$. This is also where the backscatter $S / N$ for FAIs peaks, implying that the $15 \mathrm{MHz}$ echo clumps are associated with the same structures that host the meterscale FAIs. Indeed, the typical distance to these FAIs from LWA1 is $\sim 200 \mathrm{~km}$, implying that the groups of FAIs seen within the all-sky images shown in Figs. 5-6 are consistent with sizes of a few to a few tens of kilometers.

In addition, these same size scales are consistent with wavelengths of shear instabilities thought to be the driving formation mechanism for structures associated with QP echoes (Larsen, 2000; Bernhardt, 2002). They are also consistent with the observed wavelengths of frontal struc- tures with $E_{\mathrm{s}}$ echoes imaged at $30 \mathrm{MHz}$ over Puerto Rico ( $\sim 30 \mathrm{~km}$; Hysell et al., 2004). Moreover, it is known that $\mathrm{QP}$ echoes are much more prominent within $E_{\mathrm{S}}$ layers that have substantial disparities between peak and mean densities as indicate by larger values of foEs-fbEs (see, e.g., Ogawa et al., 2002). For the data set presented here, the values for fbEs were relatively tightly clustered with a mean of $2.1 \mathrm{MHz}$ and standard deviation of $0.5 \mathrm{MHz}$. Thus, in this case, higher values of $f_{\mathrm{p}}$ can be taken as indicators of larger peak rather than blanketing densities. This makes the proffered notion of QP predominance at higher $f_{\mathrm{p}}$ all the more plausible. However, note that the temporal sampling of the LWA1 data, one $61 \mathrm{~ms}$ capture every $6 \mathrm{~min}$, precludes classification of these structures as bona fide QP echoes. It should be stressed that it is the size, spacing, and density of these, along with their association with $E_{\mathrm{s}}$, that makes them similar to the known properties of structures associated with QP echoes, not their temporal variability.

\section{Conclusions}

The outcome of the observing campaign presented here in many ways conforms with previously published results. The preferential detection of southwestward-directed, nighttime MSTIDs during $E_{\mathrm{s}}$ has been seen before (see, e.g., Helmboldt, 2012; Cosgrove, 2013). Other authors have also demonstrated enhanced $E_{\mathrm{S}}$ during heightened meteor activity (Chandra et al., 2001; Yellaiah et al., 2001). In addition, the results from the imaging of regions of backscatter from $E_{\mathrm{S}}$ FAIs largely conforms with previous observations in the Caribbean (Hysell et al., 2004, 2009; Larsen et al., 2007). However, the intriguing component of the results shown here is the trends among metrics of these phenomena and $E_{\mathrm{S}}$ reflection/plasma frequency. This is largely made possible by the unique combination of the remote sensing platforms employed, especially the wide-band, all-sky mode of LWA1. This allows for the simultaneous detection of $E_{\mathrm{S}}$ reflections of HF transmissions from WWV, VHF backscatter by $E_{\mathrm{s}}$ FAIs, and meteor trail reflections within roughly the same geographical area.

The aforementioned trends are summarized within the panels of Fig. 9. Here, the peak TEC fluctuation power from the spectra shown in Fig. 4 is plotted versus frequency in the upper left panels. Separate plots are shown for the LWA1+WWV- and BC840-based data. The abscissa are scaled such that the WWV and BC840 frequencies match for a simple virtual mirror approximation. The prevalence of $E_{\mathrm{s}}$ FAIs, quantified by the mean $55.25 \mathrm{MHz} S / N$ within the likely FAI region (marked with dotted lines in Fig. 6), is also plotted versus frequency in the middle column of panels. Similarly, the mean $S / N$ from the $55.25 \mathrm{MHz}$ maps for elevations above $30^{\circ}$ and excluding the FAI region is used to quantify meteor trail activity as a function of $f_{\mathrm{p}}$ in the right panels. Finally, the total correlated power among WWV 


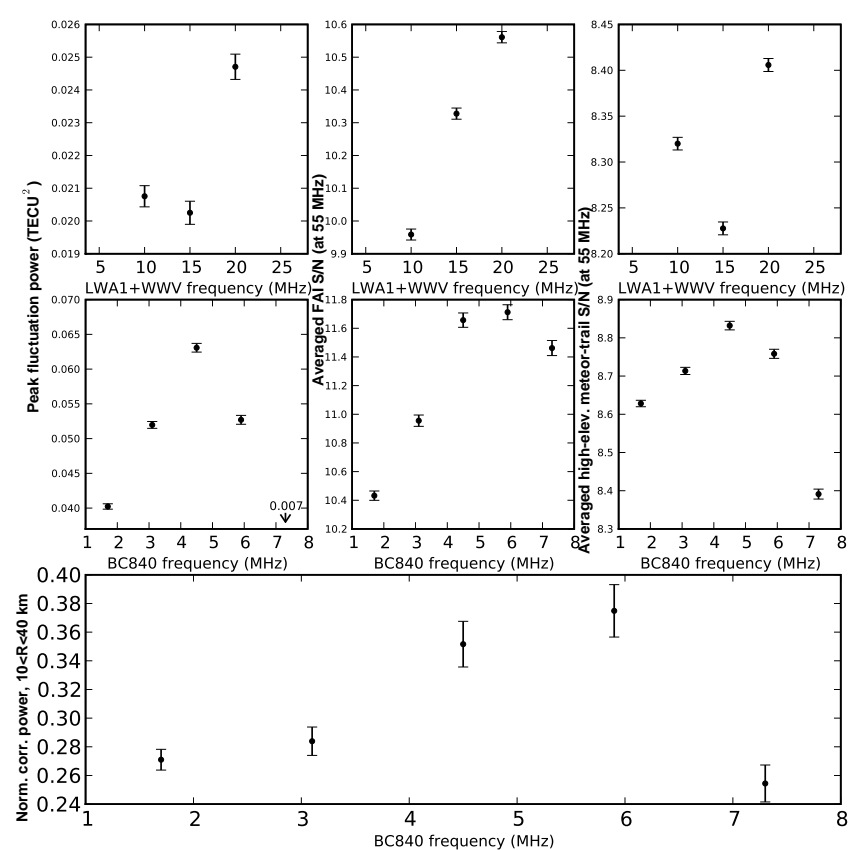

Figure 9. Several quantities plotted as functions of LWA1+WWV frequency and BC840 frequency for $E_{\mathrm{S}}$ reflections. The scales of the abscissa of the panels are set such that the LWA1+WWV and BC840 frequencies match for a simple virtual mirror approximation for the WWV reflections at a height of $110 \mathrm{~km}$. The quantities plotted along the ordinates are (left column) peak TEC fluctuation power from the spectral maps shown in Fig. 4, (middle column) the average peak $S / N$ at $55.25 \mathrm{MHz}$ for FAIs (see Fig. 5 and Sect. 2.1), (right column) the average peak $S / N$ for highelevation $\left(>30^{\circ}\right) 55.25 \mathrm{MHz}$ reflections, which are dominated by meteor trails (>80\%; see Sect. 2.1), and (lower panel) the normalized correlated power from $15 \mathrm{MHz}$ WWV sky waves on horizontal separations between 10 and $40 \mathrm{~km}$ (see Fig. 8).

$15 \mathrm{MHz}$ reflection points on horizontal scales between 10 and $40 \mathrm{~km}$ (see Sect. 3.3 and Fig. 8) is plotted versus BC840 $E_{\mathrm{s}}$ frequency in the bottom panel of Fig. 9.

Both the TEC fluctuation power and meteor trail $S / N$ correlate with $f_{\mathrm{p}}$ up to about $4.5 \mathrm{MHz}$. Beyond this limit, both trends turn over and drop substantially above $6 \mathrm{MHz}$. The FAI $S / N$ and correlated power at $15 \mathrm{MHz}$ on $10-40 \mathrm{~km}$ scales are both likewise correlated with $f_{\mathrm{p}}$. However, the trends for these two quantities remain up to higher frequencies, roughly up to $6 \mathrm{MHz}$. After this, the trends turn over, less dramatically so for the FAIs. As discussed in Sect. 3, this is consistent with the $15 \mathrm{MHz}$ echo clumps corresponding to the regions that contain the backscattering FAIs and with known properties of QP echoes.

The observations presented here clearly show that southwestward propagating MSTIDs are more common when $E_{\mathrm{s}}$ is present. By themselves, these findings cannot rule out the possibility that there is no causal relationship between these two phenomena and that they are simply both affected by the same set of underlying circumstances (e.g., the presence of
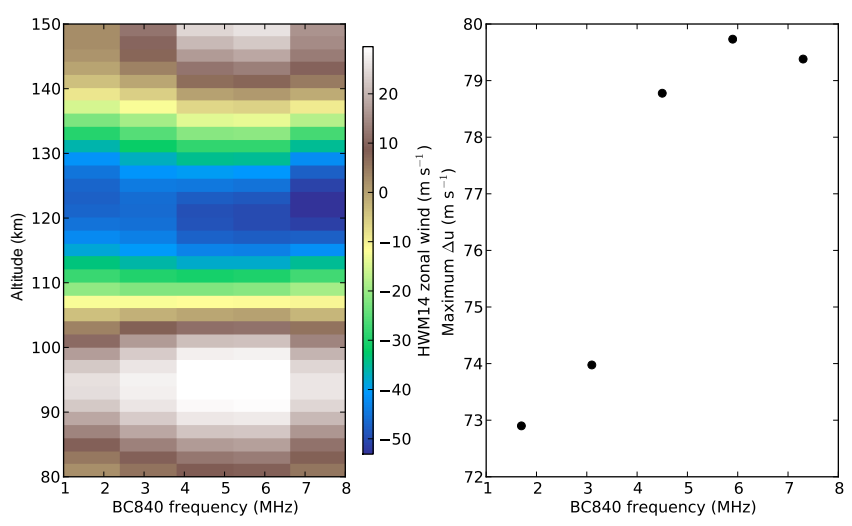

Figure 10. Left: the mean zonal wind profile computed with HWM14, weighted by BC840 ionogram $E_{\mathrm{S}}$ amplitude for five different bins of $f_{\mathrm{p}}$; right: the difference between maximum and minimum zonal wind for each $f_{\mathrm{p}}$ bin.

wind-modulated gravity waves). However, the clear trend between MSTID amplitude and $E_{\mathrm{s}}$ plasma frequency strongly implies a physical connection between the two. This connection seems to break down above $f_{\mathrm{p}} \simeq 4.5 \mathrm{MHz}$, as does the correlation between $f_{\mathrm{p}}$ and meteor activity. It is above this $f_{\mathrm{p}}$ limit where structures consistent with QP echoes are most prominent within both the 55.25 and $15 \mathrm{MHz}$ data. While there have been recent observations of concomitant MSTIDs and QP echoes (Hysell et al., 2010; Helmboldt et al., 2012), this investigation seems to indicate that these are the exception rather than the rule.

The results of this work appear to intimate that whatever physical mechanism may tie together $E_{\mathrm{s}}$ and MSTIDs must work more most efficiently with a kind of classical or quiescent $E_{\mathrm{S}}$ layer. In other words, the canonical scenario for $E_{\mathrm{s}}$ formation starts with metallic ions, deposited by ablating meteors, which are compressed into a stable and thin layer by opposing Lorentz forces within a portion of the $E$ region where the zonal wind has a negative vertical gradient. Within this formation picture, one would expect the density of such a layer to be correlated with the level of meteor activity, which it appears to be up to $f_{\mathrm{p}} \simeq 4.5 \mathrm{MHz}$.

Once such a layer has formed, if shear instabilities begin to grow, the quasi-uniform layer can be redistributed into a region of clumps and voids, similar to what Bernhardt (2002) found when calculating the impact of neutral-gas K$\mathrm{H}$ instabilities on $E_{\mathrm{s}}$ layers. In this case, the peak density of the region would depend more on the efficiency of the shear instabilities to form dense clumps than the amount of meteor-deposited heavy ions. Thus, for $E_{\mathrm{s}}$ regions with large peak densities, the correlation between $f_{\mathrm{p}}$ and meteor activity would break down and dense clumps would become more prevalent. This is precisely what was observed within the investigation presented here.

This basic paradigm is partially supported by the quiettime lower thermospheric wind conditions as described by 
the updated Horizontal Wind Model (HWM14; Drob et al., 2015). While HWM14 provides only an empirically driven, climatological representation of winds within the thermosphere and not actual measurements, it can still be used to explore how the expected neutral wind conditions within the $E$ region change with $E_{\text {s }}$ properties. HWM14 was used to compute the zonal wind profile between 80 and $150 \mathrm{~km}$ altitude near the location of LWA1 at the midpoint of each $30 \mathrm{~min}$ window used to compute the mean BC840 ionograms (see Sect. 2.2). Weighted averages of the profiles were then computed as a function of $f_{\mathrm{p}}$ in the same manner as was used for the TEC fluctuation spectra and the $55.25 \mathrm{MHz}$ all-sky images (see Sect. 3.1-3.2 and Figs. 4, 6). The profiles are shown as an image in the left panel of Fig. 10. The semidiurnaltide driven zonal wind shears expected for times when $E_{\mathrm{s}}$ is present are apparent for all values of $f_{\mathrm{p}}$. The magnitude of the shear appears to increase with $f_{\mathrm{p}}$ up to about $5-6 \mathrm{MHz}$. This is better visualized within the right panel of Fig. 10 where the difference between the maximum and minimum zonal wind is plotted as a function of $f_{\mathrm{p}}$. The pattern within this plot is quite similar to that seen for FAI backscatter $S / N$ as a function of $f_{\mathrm{p}}$ (see Fig. 9), implying that more dense groups of FAIs tend to occur at times when the zonal wind shear is expected to be more pronounced. This is consistent with the notion that these dense structures result from shear instabilities.

It should be noted that the results of this investigation are also essentially consistent with simulations of the coupled $E-F$ instability described by Cosgrove et al. (2004). Threedimensional simulations performed by Yokoyama et al. (2009) and Yokoyama and Hysell (2010) showed that when starting with a quiescent, stable $E_{\mathrm{s}}$ layer, northwest-tosoutheast aligned wavefronts form within both the $E_{\mathrm{S}}$ layer and in the $F$ region via the coupled instability. This happens even when starting with a set of random perturbations as the instability preferentially grows disturbances aligned in this way. However, the irregularities reach a relatively stable perturbation amplitude of a few percent within about $30 \mathrm{~min}$ or less, leaving the original, smooth $E_{\mathrm{s}}$ layer largely intact. Thus, while the structures formed within these simulations have wavelengths $\sim 30 \mathrm{~km}$, it seems unlikely that the dense, relatively isolated structures observed to coincide with QP echoes are formed in this way.

In fact, given the results presented here, it appears more likely that, as previously asserted (see, e.g., Larsen, 2000), these very dense structures result from shear instabilities that significantly disrupt the otherwise relatively smooth $E_{\mathrm{S}}$ layer. Such disruptions would compromise the efficiency of the interaction between polarized electric fields with the $E_{\mathrm{s}}$ and $F$ regions and could explain why MSTID activity quickly vanishes for $f_{\mathrm{p}}>5 \mathrm{MHz}$. However, it should be noted that the effectiveness of the Cosgrove et al. (2004) instability depends as much on the integrated Pedersen and Hall conductivities within the $F$ region and $E_{\mathrm{s}}$ layer, respectively, as it does on $E_{\mathrm{s}}$ layer density (see Cosgrove and Tsunoda, 2002; Cosgrove et al., 2004; Yokoyama et al., 2004). Therefore, the $E_{\mathrm{s}}$ layer density for which MSTID activity peaks may depend significantly on solar activity and may not be universally at $f_{\mathrm{p}} \sim 4$ $5 \mathrm{MHz}$.

\section{Data availability}

The unprocessed GPS data used in this investigation are publicly available in compressed RINEX format via anonymous FTP from the two databases listed in Sect. 2.2. The digisonde data for BC840 was obtained from the DIDBase repository (DIDBase, available at: http://ulcar.uml.edu/DIDBase/; Reinisch et al., 2004). Processed data, including fluctuation spectra, are available upon request to the author. Raw LWA1 data are proprietary and are not publicly available. However, all-sky images and image cubes generated from these data for this manuscript can be made available upon request to the author.

Acknowledgements. The author would like to thank the reviewers for useful comments and suggestions. The author would also like to thank D. Drob for providing code for running the HWM14 model. Basic research at the Naval Research Laboratory is supported by 6.1 base funding. Construction of the LWA has been supported by the Office of Naval Research under Contract N00014-07-C $=0147$. Support for operations and continuing development of the LWA1 is provided by the National Science Foundation under grant AST1139963 and AST-1139974 of the University Radio Observatory program.

The topical editor, K. Hosokawa, thanks two anonymous referees for help in evaluating this paper.

\section{References}

Arras, C., Jacobi, C., Wickert, J., Heise, S., and Schmidt, T.: Sporadic $E$ signatures revealed from multi-satellite radio occultation measurements, Adv. Radio Sci., 8, 225-230, doi:10.5194/ars-8225-2010, 2010.

Baggaley, W. J. and Steel, D. I.: The seasonal structure of ionosonde sporadic-E parameters and meteoroid deposition rates, Plan. Space Sci., 32, 1533-1539, doi:10.1016/0032-0633(84)90021-7, 1984.

Bernhardt, P. A.: The modulation of sporadic- $E$ layers by KelvinHelmholtz billows in the neutral atmosphere, J. Atmos. Sol.Terr. Phy., 64, 1487-1504, doi:10.1016/S1364-6826(02)00086$\mathrm{X}, 2002$.

Bowman, G. G.: Quasi-periodic scintillations at mid-latitudes and their possible association with ionospheric sporadic-E structures, Ann. Geophys., 7, 259-267, 1989.

Chandra, H., Sharma, S., Devasia, C. V., Subbarao, K. S. V., Sridharan, R., Sastri, J. H., and Rao, J. V. S. V.: Sporadic-E associated with the Leonid meteor shower event of November 1998 over low and equatorial latitudes, Ann. Geophys., 19, 59-69, doi:10.5194/angeo-19-59-2001, 2001.

Cosgrove, R.: Mechanisms for E-F coupling and their manifestation, J. Atmos. Sol.-Terr. Phy., 103, 56-65, doi:10.1016/j.jastp.2013.03.011, 2013. 
Cosgrove, R. B.: Generation of mesoscale $F$ layer structure and electric fields by the combined Perkins and $E_{\mathrm{S}}$ layer instabilities, in simulations, Ann. Geophys., 25, 1579-1601, doi:10.5194/angeo-25-1579-2007, 2007.

Cosgrove, R. B. and Tsunoda, R. T.: A direction-dependent instability of sporadic- $E$ layers in the nighttime midlatitude ionosphere, Geophys. Res. Lett. 29, 1864, doi:10.1029/2002GL014669, 2002.

Cosgrove, R. B., Tsunoda, R. T., Fukao, S., and Yamamoto, M.: Coupling of the Perkins instability and the sporadic $E$ layer instability derived from physical arguments, J. Geophys. Res.-Space, 109, A06301, doi:10.1029/2003JA010295, 2004.

Dowell, J., Wood, D., Stovall, K., Ray, P. S., Clarke, T., and Taylor, G.: The Long Wavelength Array Software Library, J. Astron. Instrum., 1, 1250006, doi:10.1142/S2251171712500067, 2012.

Drob, D. P., Emmert, J. T., Meriwether, J. W., Makela, J. J., Doornbos, E., Conde, M., Hernandez, G., Noto, J., Zawdie, K. A., McDonald, S. E., Huba, J. D., and Klenzing, J. H.: An update to the Horizontal Wind Model (HWM): The quiet time thermosphere, Earth Space Sci., 2, 301-319, doi:10.1002/2014EA000089, 2015.

Ellingson, S. W., Taylor, G. B., Craig, J., Hartman, J., Dowell, J., Wolfe, C. N., Clarke, T. E., Hicks, B. C., Kassim, N. E., Ray, P. S., Rickard, L. J., Schinzel, F. K., and Weiler, K. W.: The LWA1 Radio Telescope, IEEE T. Antenn. Propag., 61, 25402549, doi:10.1109/TAP.2013.2242826, 2013.

Haldoupis, C.: Midlatitude Sporadic E. A Typical Paradigm of Atmosphere-Ionosphere Coupling, Space Sci. Rev., 168, 441461, doi:10.1007/s11214-011-9786-8, 2012.

Haldoupis, C., Pancheva, D., Singer, W., Meek, C., and MacDougall, J.: An explanation for the seasonal dependence of midlatitude sporadic E layers, J. Geophys. Res.-Space, 112, A06315, doi:10.1029/2007JA012322, 2007.

Helmboldt, J. F.: Insights into the nature of northwest-to-southeast aligned ionospheric wavefronts from contemporaneous Very Large Array and ionosonde observations, J. Geophys. Res.Space, 117, A07310, doi:10.1029/2012JA017802, 2012.

Helmboldt, J. F. and Intema, H. T.: Advanced spectral analysis of ionospheric waves observed with sparse arrays, J. Geophys. Res.Space, 119, 1392-1413, doi:10.1002/2013JA019162, 2014.

Helmboldt, J. F., Lazio, T. J. W., Intema, H. T., and Dymond, K. F.: A new technique for spectral analysis of ionospheric TEC fluctuations observed with the Very Large Array VHF system: From QP echoes to MSTIDs, Radio Sci., 47, RSOL02, doi:10.1029/2011RS004787, 2012.

Helmboldt, J. F., Clarke, T. E., Craig, J., Dowell, J. D., Ellingson, S. W., Hartman, J. M., Hicks, B. C., Kassim, N. E., Taylor, G. B., and Wolfe, C. N.: Passive all-sky imaging radar in the HF regime with WWV and the first station of the Long Wavelength Array, Radio Sci., 48, 491-512, doi:10.1002/rds.20056, 2013.

Helmboldt, J. F., Ellingson, S. W., Hartman, J. M., Lazio, T. J. W., Taylor, G. B., Wilson, T. L., and Wolfe, C. N.: All-sky imaging of meteor trails at $55.25 \mathrm{MHz}$ with the first station of the Long Wavelength Array, Radio Sci., 49, 157-180, doi:10.1002/2013RS005220, 2014.

Hernández-Pajares, M., Juan, J. M., and Sanz, J.: Medium-scale traveling ionospheric disturbances affecting GPS measurements: Spatial and temporal analysis, J. Geophys. Res.-Space, 111, A07S11, doi:10.1029/2005JA011474, 2006.
Hicks, B. C., Paravastu-Dalal, N., Stewart, K. P., Erickson, W. C., Ray, P. S., Kassim, N. E., Burns, S., Clarke, T., Schmitt, H., Craig, J., Hartman, J., and Weiler, K. W.: A Wide-Band, Active Antenna System for Long Wavelength Radio Astronomy, Pub. Astro. Soc. Pac., 124, 1090-1104, doi:10.1086/668121, 2012.

Hocking, W. K., Fuller, B., and Vandepeer, B.: Real-time determination of meteor-related parameters utilizing modern digital technology, J. Atmos. Sol.-Terr. Phy., 63, 155-169, doi:10.1016/S1364-6826(00)00138-3, 2001.

Hysell, D. L., Larsen, M. F., and Zhou, Q. H.: Common volume coherent and incoherent scatter radar observations of mid-latitude sporadic E-layers and QP echoes, Ann. Geophys., 22, $3277-$ 3290, doi:10.5194/angeo-22-3277-2004, 2004.

Hysell, D. L. and Burcham, J. D.: HF radar observations of quasiperiodic E layer echoes over North America, J. Geophys. Res., 104, 4361-4372, doi:10.1029/1998JA900144, 1999.

Hysell, D. L., Nossa, E., Larsen, M. F., Munro, J., Sulzer, M. P., and González, S. A.: Sporadic E layer observations over Arecibo using coherent and incoherent scatter radar: Assessing dynamic stability in the lower thermosphere, J. Geophys. Res.-Space, 114, A12303, doi:10.1029/2009JA014403, 2009.

Hysell, D. L., Yokoyama, T., Nossa, E., Hedden, R. B., Larsen, M. F., Munro, J., Smith, S., Sulzer, M. P., and Gonzàlez, S. A.: Radar and optical observations of irregular midlatitude sporadic $E$ layers beneath MSTIDs, in: Aeronomy of the Earth's Atmosphere and Ionosphere, edited by: Hultqvist, B., Abdu, M. A., Pacheva, D., and Bhattacharyya, A., IAGA Special Sopron Book Series, 2010.

Hysell, D. L., Nossa, E., Larsen, M. F., Munro, J., Smith, S., Sulzer, M. P., and GonzáLez, S. A.: Dynamic instability in the lower thermosphere inferred from irregular sporadic E layers, J. Geophys. Res.-Space, 117, A08305, doi:10.1029/2012JA017910, 2012.

Larsen, M. F.: A shear instability seeding mechanism for quasiperiodic radar echoes, J. Geophys. Res., 105, 24931-24940, doi:10.1029/1999JA000290, 2000.

Larsen, M. F., Hysell, D. L., Zhou, Q. H., Smith, S. M., Friedman, J., and Bishop, R. L.: Imaging coherent scatter radar, incoherent scatter radar, and optical observations of quasiperiodic structures associated with sporadic $E$ layers, J. Geophys. Res.-Space, 112, A06321, doi:10.1029/2006JA012051, 2007.

Miller, K. L. and Smith, L. G.: Incoherent scatter radar observations of irregular structure in mid-latitude sporadic $E$ layers, J. Geophys. Res., 83, 3761-3775, doi:10.1029/JA083iA08p03761, 1978.

Nelson, G. K., Lombardi, M. A., and Okayama, D. T.: NIST time and frequency radio stations: WWV, WWVH, and WWVB, NIST Special Publication, 250-267, 2005.

Ogawa, T., Takahashi, O., Otsuka, Y., Nozaki, K., Yamamoto, M., and Kita, K.: Simultaneous middle and upper atmosphere radar and ionospheric sounder observations of midlatitude E region irregularities and sporadic $E$ layer, J. Geophys. Res.-Space, 107, 1275, doi:10.1029/2001JA900176, 2002.

Pan, C. J. and Tsunoda, R. T.: Quasi-periodic echoes observed with the Chung-Li VHF Radar during the SEEK Campaign, Geophys. Res. Lett., 25, 1809-1812, doi:10.1029/98GL00302, 1998.

Perkins, F.: Spread $F$ and ionospheric currents, J. Geophys. Res., 78, 218-226, doi:10.1029/JA078i001p00218, 1973. 
Reinisch, B. W., Galkin, I. A., Khmyrov, G., Kozlov, A., and Kitrosser, D.: Automated collection and dissemination of ionospheric data from the digisonde network, Adv. Radio Sci., 2, 241-247, 2004.

Taylor, G. B., Ellingson, S. W., Kassim, N. E., Craig, J., Dowell, J., Wolfe, C. N., Hartman, J., Bernardi, G., Clarke, T., Cohen, A., Dalal, N. P., Erickson, W. C., Hicks, B., Greenhill, L. J., Jacoby, B., Lane, W., Lazio, J., Mitchell, D., Navarro, R., Ord, S. M., Pihlström, Y., Polisensky, E., Ray, P. S., Rickard, L. J., Schinzel, F. K., Schmitt, H., Sigman, E., Soriano, M., Stewart, K. P., Stovall, K., Tremblay, S., Wang, D., Weiler, K. W., White, S., and Wood, D. L.: First Light for the First Station of the Long Wavelength Array, J. Astron. Instrum., 1, 1250004, doi:10.1142/S2251171712500043, 2012.

Tolman, B., Harris, R. B., Gaussiran, T., Munton, D., Little, J., Mach, R., Nelsen, S., and Renfro, B.: The GPS Toolkit: Open Source GPS Software, 16th International Technical Meeting of the Satellite Division of the Institute of Navigation, Long Beach, California, 9-12 September 2003, 2004.

Tsugawa, T., Otsuka, Y., Coster, A. J., and Saito, A.: Medium-scale traveling ionospheric disturbances detected with dense and wide TEC maps over North America, Geophys. Res. Lett., 34, L22101, doi:10.1029/2007GL031663, 2007.
Webster, A. R., Brown, P. G., Jones, J., Ellis, K. J., and CampbellBrown, M.: Canadian Meteor Orbit Radar (CMOR), Atmos. Chem. Phys., 4, 679-684, doi:10.5194/acp-4-679-2004, 2004.

Whitehead, J. D.: Recent work on mid-latitude and equatorial sporadic- E, J. Atmos. Terr. Phys., 51, 401-424, 1989.

Yellaiah, G., Suresh, K., and Raghavender, B.: Study of Es occurrences during meteor shower periods at Hyderabad by using FM radio signals, B. Astron. Soc. India, 29, 251-257, 2001.

Yokoyama, T. and Hysell, D. L.: A new midlatitude ionosphere electrodynamics coupling model (MIECO): Latitudinal dependence and propagation of medium-scale traveling ionospheric disturbances, Geophys. Res. Lett., 37, L08105, doi:10.1029/2010GL042598, 2010.

Yokoyama, T., Horinouchi, T., Yamamoto, M., and Fukao, S.: Modulation of the midlatitude ionospheric $\mathrm{E}$ region by atmospheric gravity waves through polarization electric field, J. Geophys Res.-Space, 109, A12307, doi:10.1029/2004JA010508, 2004.

Yokoyama, T., Hysell, D. L., Otsuka, Y., and Yamamoto, M.: Threedimensional simulation of the coupled Perkins and $E_{\mathrm{S}}$-layer instabilities in the nighttime midlatitude ionosphere, J. Geophys. Res.-Space, 114, A03308, doi:10.1029/2008JA013789, 2009. 